\title{
Family Physicians' Work Load, Personal Protection and Isolation Behaviors in the COVID-19 Pandemic
}

\author{
Zerrin Gamsizkan ${ }^{1(\mathbb{D})}$ \\ ${ }^{1}$ Department of Family Medicine, Duzce University, Medical Faculty, Duzce, Turkey
}

Copyright@ Author(s) - Available online at https://dergipark.org.tr/en/pub/mbsjohs

Content of this journal is licensed under a Creative Commons Attribution-NonCommercial 4.0 International License,

Received: 19 August 2021, Accepted: 25 August 2021, Published online: 31 August 2021 (C) Ordu University Institute of Health Sciences, Turkey, 2021

\begin{abstract}
Objective: COVID-19 pandemic, which has been affecting the world for months, has affected health workers both in terms of working conditions and personal lifestyle. The aim of this study is to identify the changing workload of family physicians actively working in our country and to determine the factors affecting social protection behaviors.

Methods: Between March 2020 and April 2020, a survey of 20 questions was conducted for family physicians via google forms.

Results: Data of 392 Physicians, 52.8\% $(\mathrm{n}=207)$ female and $47.2 \%(\mathrm{n}=185)$ male, were included in the study. While $33.4 \%(\mathrm{n}=131)$ stated that they lived in the same house but in a different room with their families, $48.2 \%(\mathrm{n}=189)$ stated that they applied social distance by staying at least one meter away from their families. If physicians had children, they applied social isolation significantly more $(\mathrm{p}<0.001)$. Having relatives with a chronic illness at home also resulted in a significant increase in social isolation $(\mathrm{p}<0.001)$. Family physicians stated that they spend an average of 1.8 (Min1-Max 3) hours per day for the purpose of guiding patients both at home and for other needs.

Conclusions: Primary care medicine has adapted to the situation by taking protective measures quickly in this pandemic, which has shaken the World. Family Physicians, whose most important task is preventive health service, performed their tasks in the follow-up and implementation of quarantine and home monitoring, even though they were sometimes away from their families.

Key words: Pandemic, Family physician, COVID-19, Personal protection, Social isolation
\end{abstract}

Suggested Citation: Gamsizkan Z. Family Physicians' work Load, Personal Protection and Isolation Behaviors in the COVID-19 Pandemic Mid Blac Sea Journal of Health Sci, 2021; 7(2):289-295

\section{Address for correspondence/reprints:}

\section{Zerrin Gamsizkan}

Telephone number: +90 (380) 5421390 (ext.6513)

E-mail: zgamsizkan@yahoo.com 


\section{Introduction}

We are in a period where the importance of words and concepts has experienced more confusion than ever before. In the next process, pandemic, selfprotection, public health, global threat now seems to be the concepts that humanity will deal with for a long time. Along with the global threat, guidelines have been prepared by the health ministries and institutions of all countries to create the healthiest algorithm for the pandemic (1). While people are recommended to stay at home for self-protection in this period, it is stated that healthcare workers who must serve by taking all kinds of risks are at risk both physically and psychologically (2). It is reported that healthcare professionals have difficulty in striking a balance between not infecting their family with the virus and their obligation to serve patients in the pandemic (3).

Due to the fact that the vast majority of healthcare workers at the Zhongnan hospital in Wuhan were infected with the virüs, it was suggested healthcare professionals must use personal protective equipment (PPE) to protect themselves (4). Faced with a burden that pushes the hospital conditions in this extraordinary pandemic, health systems started to use the way to follow infected patients with good general condition and contact cases at home. In the guide prepared in England, the family physicians working in primary care are provided with algorithms that help to diagnose the disease quickly. In the same guideline, family physicians were advised to assess patients online or by telephone, and to observe patients who are monitored in home isolation (5).

Remote patient management in primary care has been used as a method with important gains for many years (6). In our country, Family physicians working within the scope of biopsychosocial approach to their patients also serve their patients remotely when necessary.

According to the results of the studies conducted in the pandemic, the presence of chronic disease, the association of diseases that suppress the immune system are the conditions that affect mortality the most $(7,8)$. In this pandemic, it is an important service that family physicians provide remote counseling to patients with chronic diseases. In addition to overseeing patient health in pandemics, patient control over the phone has a major contribution to public health (9).

The purpose of this study is to discuss the contribution of family physicians working in pandemic to preventive healthcare by evaluating the changing patient profile and working habits in the new period. Another aim of the study is to identify personal protective measures depending on the patient load, and social isolation behaviors with their family.

\section{Methods}

\section{Study design}

The study was planned descriptively in crosssection.After creating the hypothesis of the study, the Ethics committee application files were sent online to the relevant institutions and obtained for study permission. Data collection tools were shaped during the permission waiting process. A 20-question survey was created by researchers and was delivered to physicians through various communication networks. The survey questions used in the study were prepared based on the articles published in the early stages of the pandemic. In the survey created, the physicians were asked about age, gender, the city they work in, the use of personal protective equipment, social isolation behavior, the number of covid positive and covid contact patients, and the daily working time spent on the telephone.

\section{Participants}

Working active in primary care was determined as a criterion for inclusion in the study. The survey created for the study was sent to approximately 1100 family physicians working in different patient burdens. The physcians were given time to fill in the survey, considering the workload. The responses of family physicians who filled the survey sent were included in the study.

\section{Study period}

It took approximately 2 months between the dates of March 2020 and May 2020 to plan the study, obtain the permission of the ethics committee and collect the data. Permission was obtained from the Ministry of Health and Duzce University Ethics Committee for the study. (Approval No: 2020/78)

\section{Statistical analysis}

Statistical analysis for the study was made in SPSS 22.0 for Windows package program. Descriptive statistics are expressed as mean \pm standard deviation for numerical variables, number, and percentage for categorical variables. Kolmogorov Smirnov test was used to investigate the suitability of the data for normal distribution. In comparison of the data, Pearson Chi-square was used depending on the expected value rule for categorical variables and Independent Sample Test was used for numerical variables. For statistical significance, $p<0.05$ value was accepted as a criterion. 


\section{Results}

For the study, the survey was sent to 1100 family physicians working in different cities. The response rate was \%35.6 $(\mathrm{n}=392)$ for the study. 52.8\% $(\mathrm{n}=$ 207) female and $47.2 \%(n=185)$ male physician, who completed the survey sent to our study, with an average age of 40.24 , were included. While $53.8 \%$ (n $=211$ ) of the physicians participating in our study were working in small, populated provinces, $46.2 \%$ $(\mathrm{n}=181)$ working in cities with large populations. While $66.8 \%(\mathrm{n}=262)$ physicians were in the city center, $23.0 \%(\mathrm{n}=90)$ were in the district and $10.2 \%$ $(n=40)$ were in the village. $11.2 \%(n=44)$ of the physicians had a chronic disease; $4.3 \%(\mathrm{n}=17)$ were hypertension, $3.1 \%(\mathrm{n}=12)$ were diabetes, $2.3 \%(\mathrm{n}=$ 9) were asthmatic, $1.5 \%(n=6)$ were using immunosuppressive agents. $8.6 \%(\mathrm{n}=34)$ of the physicians stated that they lived in a place separate from their home while working in the pandemic. While $33.4 \%(n=131)$ stated that they lived in the same house but in a different room with their family, 48.2\% ( $\mathrm{n}=189)$ stated that they applied social distance by staying at least one meter away from their family. 9.7\% $(\mathrm{n}=38)$ of physicians stated that they do not practice any social distance between their families.

$89.3 \%(\mathrm{n}=350)$ of physicians used masks while working, 55.6\% $(\mathrm{n}=218)$ gloves, $35.2 \%(\mathrm{n}=138)$ protective glasses, $26.0 \%(\mathrm{n}=102)$ visor, $14.5 \%(\mathrm{n}=$
57) of them stated that they used protective overalls (Table 1).

The average number of covid positive patients followed by the pandemic since the beginning of the pandemic was 9.6 (Min 2- Max 40), the average number of covid contact patients was 37.38 (Min 2Max 140), the average number of seasonal influenza patients was 5.64 (Min. 0-Max 20). In addition, 4.07 (Min 0- Max 20) patients stated that they provided prescriptions, reports and remote guidance services for various chronic conditions as well as for chronic disease. Family physicians stated that they spend an average of 1.8 (Min1-Max 3) hours per day for the purpose of guiding patients both at home and for other needs (Table 2).

There was no difference in terms of protective equipment type used according to the age and gender of the physicians. If physicians had children, they applied social isolation significantly more $(\mathrm{p}<0.001)$. Having relatives with a chronic illness at home also resulted in a significant increase in social isolation $(p<0.001)$. There was no significant difference according to the use of protective equipment between family physicians working in cities where more crowded cities and more covid positive cases were seen and working in cities where fewer cases were seen (Table 3).

Table 1. Dynamics and Prevention Behaviors of Physicians in the Pandemic Process

\begin{tabular}{|c|c|c|}
\hline & Descriptive Results & Frequencies \\
\hline Age & $40.24 \pm 8.85$ & \\
\hline \multirow[t]{2}{*}{ Gender } & Male & 185 \\
\hline & Female & 207 \\
\hline \multirow[t]{2}{*}{$\begin{array}{l}\text { Number of Physicians according to the city } \\
\text { population }\end{array}$} & High-population city & 181 \\
\hline & Low population city & 211 \\
\hline \multirow[t]{2}{*}{ Chronic disease of physicians } & Yes & 44 \\
\hline & No & 348 \\
\hline \multirow[t]{4}{*}{ Chronic disease type } & Hypertension & 17 \\
\hline & Diabetes & 12 \\
\hline & Asthma & 9 \\
\hline & Immune suppressive disease & 6 \\
\hline \multirow[t]{4}{*}{ Social izolation } & Separate house & 34 \\
\hline & Same house 1 meter social distance & 189 \\
\hline & Same house in a separate room & 131 \\
\hline & No isolation & 38 \\
\hline \multirow[t]{5}{*}{ PPE } & Mask & 350 \\
\hline & Gloves & 218 \\
\hline & Goggles & 138 \\
\hline & Visors & 102 \\
\hline & Protective overalls & 57 \\
\hline
\end{tabular}


Table 2. Patient Profile of Family Physicians During the Pandemic.

\begin{tabular}{lll}
\hline & \multicolumn{1}{c}{ Mean } & \multicolumn{1}{c}{ Min- Max } \\
\hline Covid positive patient (Follow-up at home) & 9.6 & $2-40$ \\
Covid contact patient (Follow-up at home) & 37.38 & $2-140$ \\
Patient in need of remote service & 4.07 & $0-20$ \\
Time spent on telephone service (hours) & 1.80 & $1-3$ \\
\hline
\end{tabular}

Table 3. Physician's age, gender, covid positive and contact number of patient follow-ups, protective equipment and social isolation practice

\begin{tabular}{|c|c|c|}
\hline & & $\mathrm{P}$ \\
\hline \multirow[t]{5}{*}{ Age } & Mask & $0.006^{*}$ \\
\hline & Goggles & $0.882^{*}$ \\
\hline & Gloves & $0.850^{*}$ \\
\hline & Visors & $0.333^{*}$ \\
\hline & Protective overalls & $0.030 *$ \\
\hline \multirow[t]{5}{*}{ Gender } & Mask & $0.411^{\dagger}$ \\
\hline & Goggles & $0.978^{\dagger}$ \\
\hline & Gloves & $0.320^{\dagger}$ \\
\hline & Visors & $0.469^{\dagger}$ \\
\hline & Protective overalls & $0.752^{\dagger}$ \\
\hline The presence of children at home & Social isolation & $0.001^{\dagger}$ \\
\hline $\begin{array}{l}\text { Living with a relative with chronic } \\
\text { disease at home }\end{array}$ & Social isolation & $<0.001^{\dagger}$ \\
\hline High number of covid cases & Social isolation & $0.142^{\dagger}$ \\
\hline High number of covid cases & PPE & $0.512^{\dagger}$ \\
\hline
\end{tabular}

\section{Discussion}

In the study, it was observed that family physicians took into account the use of PPE. While the most used PPE is determined as a mask, physicians generally was preferring to use more than one PPE. It is also emphasized in other studies that family physicians, who are the first point of contact with the patient, adopt to use protective materials to protect themselves in viral pandemics $(10,11)$. Talking about the risk of contamination in various study units, Chersich and colleagues say that healthcare professionals in primary care may have difficulties in maintaining social distance, where there is a heavy patient burden (12). Family physicians who are at risk in contact with cases that have not been diagnosed yet usually feel uneasy (13). Until an effective vaccine and drug against the new type of corona virus is found the best known safeguard measure is social distance and hygiene rules. In this context, it is emphasized that family physicians following infants and pregnant patients should pay attention to the rules of prevention (14).

According to the results of the study, family physicians spend a part of their daily work by telephone for guidance and patient follow-up. Just before the pandemic has not become widespread throughout the country, The Ministry of Health has published an implementation guide for the follow-up of covid positive patients and their relatives (15). According to this guide, the covid positive patients and their relatives of which no hospitalization is required with good general condition, will be kept and followed-up in their homes for 14 days. In order to prevent the spread of pandemics, a decision was made to prevent patients over 65 years old and chronic diseases from leaving the home. While the social 
needs of elderly and chronic patients who could not go out were met by local administrations, their health needs were met by primary care health workers (16). In this period, the most important function of family physicians was to monitor the patients 'and their relatives' symptoms and health status by calling their patients every day to prevent the spread of pandemics. In addition to covid positive and covid contact patient follow-up, they stated that they performed remote triage and evaluation for their patients who were at risk of coming out and coming to the healthcare institution. Triage by phone for cancer patients, who are in the patient group, elimination of some simple complaints remotely, and the preparation of reports and prescriptions, when necessary, are the proposed advantages during this pandemic period (17).

Before the COVID-19 pandemic, Telemedicine was used and recommended as an application with many promising advantages (18). Having a tool that patients can consult with their physicians in real time is even more important in this pandemic. It is predicted that telemedicine applications that will help reduce transmission during the pandemic period will be used increasingly (19). Providing the use of telemedicine, which is said to change the traditional medical approach, in a more organized and safe way in future pandemics is one of the most trending topics of today (20). For family physicians who support their patients with chronic diseases by remote health care, it is recommended to create regulatory guides for the applications to be performed while meeting their needs especially during the pandemic period (21). The social isolation applied among the relatives of the physicians participating in the study is also striking. Physicians who have children at home or have a chronic disease show more behavior to isolate themselves from their relatives. In the H1N1 pandemic in 2010, it was reported that health care workers who have the same concerns experience intense anxiety about both their own health and the health of their families (22) In the study some physicians also stated that they preferred to stay in a different place by separating the house with their relatives when they worked in the pandemic.

The Second Xiangya Hospital and Mental Health Institute, which provides isolated resting areas for healthcare professionals to reduce their psychological effects and fears about this issue, considers social isolation behaviors from their relatives, as natural and somewhat relaxing (23). It is emphasized that primary care services, which has a key contribution in the spread of the pandemic as the first meeting point with the patient, although it has limited test possibilities, will continue to alleviate the tertiary health burden (24). Family Physicians, the primary duty of which is preventive health care, has performed the most important tasks in this pandemic, which threatens the health of people, in following up and implementing quarantine and home monitoring procedures.

\section{Limitations}

The study had some limitations. Most importantly, since it is a cross-sectional study, the results cannot be generalized to the whole country and family physicians. Another limitation is that the patient data stated by the doctors were not checked from the database. The number of patients followed by doctors is based on their individual statements.

\section{Conclusion}

The results of the study showed that family physicians spent a significant part of their daily work during the pandemic period with home covid patients and patients with covid contact for remote monitoring. In this context, it is a very important support in pandemic control that they contribute to the studies of filiation, which is the most important step in preventing pandemic spread. In addition, it has been determined that they provide remote guidance and counseling by dealing with patients with chronic diseases or immunocompromised patients who are inconvenient to leave the house. Primary care physicians, who are the most trusted healthcare professionals of patients who are afraid to go to health institutions in order not to meet the new type of corona virus, will also play a key role in the pandemic waves that may occur.

Ethics Committee Approval: This study was conducted with the approval of the ethics committee of Duzce University Faculty of Medicine, NonInvasive Clinical Research Ethics Committee. (Ethics Committee date and Decision no: (date: 11.05.2020/no:2020/78)

Peer-review: Externally peer-reviewed. Author Contributions:

Idea, Design, Audit, Data Collection and/or Processing, Analysis and/or Interpretation, Writing, Z G

Conflict of Interest: No conflict of interest was declared by the author.

Financial Disclosure: The author declared that this study hasn't received no financial support. 


\section{References}

1. Greenhalgh T, Koh GCH, Car J. Covid-19: a remote assessment in primary care. BMJ 2020;25;368:m1182.

2. The Lancet. COVID-19: protecting health-care workers. Lancet 2020;395(10228): 922.

3. McConnell D. Balancing the duty to treat with the duty to family in the context of the COVID-19 pandemic. J Med Ethics 2020;46(6):360-3.

4. Chu J, Yang N, Wei Y, Yue H, Zhang F, He L, et al. Clinical characteristics of 54 medical staff with COVID-19: A retrospective study in a single center in Wuhan, China. J Med Virol 2020;92(7):807-13

5. Razai MS, Doerholt K, Ladhani S, Oakeshott P. Coronavirus disease 2019 (covid-19): a guide for UK GPs [published correction appears in BMJ 2020 Mar 11;368:m989] [published correction appears in BMJ 2020;7;369:m1398]. BMJ 2020;368:m800.

6. Bashshur RL, Howell JD, Krupinski EA, Harms KM, Bashshur N, Doarn CR. The Empirical Foundations of Telemedicine Interventions in Primary Care. Telemed J E Health 2016;22(5):342-75.

7. Hussain A, Bhowmik B, do Vale Moreira NC. COVID-19 and diabetes: Knowledge in progress. Diabetes Res Clin Pract 2020;162:108142.

8. Wang L, He W, Yu X, Hu D, Bao M, Liu H, et al. Coronavirus disease 2019 in elderly patients: Characteristics and prognostic factors based on 4week follow-up. J Infect 2020; 80(6):639-45.

9. Annis T, Pleasants S, Hultman G, Lindemann E, Thompson JA, Billecke S, et al. Rapid implementation of a COVID-19 remote patient monitoring program. J Am Med Inform Assoc 2020;27(8):1326-30.

10.Yu EYT, Leung WLH, Wong SYS, Liu KSN, Wan EYF; HKCFP Executive and Research Committee. How are family doctors serving the Hong Kong community during the COVID-19 outbreak? A survey of HKCFP members. Hong Kong Med J 2020;26(3):176-83.

11. Suleiman A, Bsisu I, Guzu H, Santarisi A, Alsatari M, Abbad A, et al. Preparedness of Frontline Doctors in Jordan Healthcare Facilities to COVID-19 Outbreak. Int J Environ Res Public Health 2020;17(9):3181. Published 2020 May 2.

12.Chersich MF, Gray G, Fairlie L, Eichbaum Q, Mayhew S, Allwood B, et al. COVID-19 in Africa: care and protection for frontline healthcare workers. Global Health 2020;16(1):46.
13.Canova V, Lederer Schläpfer H, Piso RJ, Droll A, Fenner L, Hoffmann T, et al. Transmission risk of SARS-CoV-2 to healthcare workers observational results of a primary care hospital contact tracing. Swiss Med Wkly 2020; 150:w20257. Published 2020 Apr 25.

14. Verbeek JH, Rajamaki B, Ijaz S, Sauni R, Toomey E, Blackwood B, et al. Personal protective equipment for preventing highly infectious diseases due to exposure to contaminated body fluids in healthcare staff. Cochrane Database Syst Rev 2020;4(4):CD011621. Published 2020 Apr 15.

15.Ministry of Health (2020). COVID-19 Algoritmalar [online]. Website: https://covid19bilgi.saglik.gov.tr/tr/algoritmalar [accessed 17April 2020]

16.Demirbilek Y, Pehlivantürk G, Özgüler ZÖ, Alp Meşe E. COVID-19 outbreak control, example of ministry of health of Turkey. Turk J Med Sci 2020;50(SI-1):489-94.

17. Scarcia M, Ludovico GM, Fortunato A, Fiorentino A. Patients with cancer in the COVID-19 era: the clinical trial issue. Tumori 2020;106(4):271-2.

18. Weinstein RS, Krupinski EA, Doarn CR. Clinical Examination Component of Telemedicine, Telehealth, mHealth, and Connected Health Medical Practices. Med Clin North Am 2018;102(3):533-44.

19. Hare N, Bansal P, Bajowala SS, Abramson S, Chervinskiy S, Corriel R, et al. Work Group Report: COVID-19: Unmasking Telemedicine. J Allergy Clin Immunol Pract 2020;8(8):2461-73

20.Murillo-Escobar MA， Cardoza-Avendaño L, López-Gutiérrez RM, Cruz-Hernández C. A Double Chaotic Layer Encryption Algorithm for Clinical Signals in Telemedicine. Journal of Medical Systems 2017;41(4):59.

21.Krznarić Ž, Bender DV, Laviano A, Cuerda C, Landi F, Monteiro R, et al. A simple remote nutritional screening tool and practical guidance for nutritional care in primary practice during the COVID-19 pandemic. Clin Nutr 2020;39(7):1983-7

22.Goulia P, Mantas C, Dimitroula D, Mantis D, Hyphantis T. General hospital staff worries, perceived sufficiency of information and associated psychological distress during the A/H1N1 influenza pandemic. BMC Infect Dis 2010;10:322. Published 2010 Nov 9. 
23. Chen Q, Liang M, Li Y, Guo J, Fei D, Wang L, et al. Mental health care for medical staff in China during the COVID-19 outbreak [published correction appears in Lancet Psychiatry. 2020 May;7(5):e27]. Lancet Psychiatry 2020; 7(4): e15e16.

24.Lam LTM, Chua YX, Tan DHY. Roles and challenges of primary care physicians facing a dual outbreak of COVID-19 and dengue in Singapore [published online ahead of print, 2020 May 6]. Fam Pract 2020; cmaa047. 